\title{
Lo que arde en Candelaria es la vida
}

\author{
Candelaria | Jhonny Hendrix Hinestroza | 2018
}

\section{Dalia Virgilí Pino*}

\author{
AIFAN (Atención Integral a la Familia, el adulto y el menor) y \\ PAUSA (Psicoanálisis Aplicado a las Urgencias Subjetivas)
}

Recibido 10 de septiembre de 2021; aprobado 28 de octubre de 2021

\begin{abstract}
Resumen
La definición de lo femenino como goce constituye el punto de partida del artículo. Se despliegan lógica y consecuencia de tal definición, así como las resonancias con algunas autoras del feminismo de la diferencia. Se toma como referencia la película Candelaria, de coproducción latinoamericana y dirigida por Jhonny Hendrix Hinestroza, para dar cuenta de las dificultades de captación del Goce Otro ya sea por la mirada o cualquier vertiente pulsional, así como por el lenguaje.
\end{abstract}

Palabras Clave: goce femenino $\mid$ Otro $\mid$ feminismo $\mid$ mirada

What burns in Candelaria is life

\begin{abstract}
The definition of the feminine as jouissance constitutes the starting point of the article. Logic and consequence of such definition unfold, also the resonances with some authors of difference feminism. The film Candelaria, a latin american co-production and directed by Jhonny Hendrix Hinestroza, is taken as a reference to account for the difficulties of capturing the feminine jouissance, either through the gaze or any instinctual aspect as well as through language.
\end{abstract}

Keywords: feminine jouissance | Other | feminism | look

\section{Lo femenino lacaniano es un goce:}

Cuando Lacan dice en los años 70 que LA Mujer no existe hace una declaración que hoy podemos leer retroactivamente como feminista, si es que nos animamos a leerla a la letra.

Su planteo va de la mano de lo que distingue al feminismo de la diferencia. Una de sus voces vivas, la española Victoria Sendón de León lo plantea así:

Para analizar la realidad hay que huir de lo neutro porque ese universal es siempre parcial. Nosotras, las mujeres, no pertenecemos a ese Género Humano ni al Sujeto Universal. Pero también hemos de escapar del genérico mujer, con mayúscula, porque no podemos ser Sujetos desde lo genérico. ¿Por qué? Porque lo genérico engendra identidades, que es precisamente lo opuesto a diferencias. (...) Desde las diferencias que nos constituyen como mujeres, tendremos que construir políticamente un Sujeto Diferencial.... que no ha de ser un sujeto genérico porque no somos idénticas...en definitiva ese sujeto diferencial femenino, es el sujeto que corresponde a las mujeres y no a la Mujer (Sendón de León, 2012, pp. 52-54).
Con estas resonancias podríamos pensar incluso que el radical planteo lacaniano antecede a los del feminismo negro e interseccional, que alegan en las voces de Audre Lorde o Bell Hook que lo único que comparten las mujeres es la opresión, si bien no la misma.

Hay una anécdota narrada por Catherine Millot que ilumina muy bien el punto de vista lacaniano en relación a las mujeres y su condición de oprimidas: "Un día le estaba hablando de lo que yo vivía como lo duro de ser mujer y él me dijo: -En esto no estás sola, lo cual no hace que lo estés menos" (Millot, 2016, p. 51).

Luego del dictado del Seminario 18 Lacan (2009 [1970-1971]) continúa su empeño en construir un discurso que no fuera de semblantes. Avanza decididamente hacia lo real y distribuye la diferencia sexual en modos de goce, acuñando un término de crucial valor clínico: sexuación. Dicho término condensa otros: elección, posición subjetiva, posibilidades relacionales y el más importante concepto producido por el psicoanálisis: el goce. 
Trasciende así a lo imaginario y lo simbólico, es decir al género. Para él no se trata ni del imaginario corporal ni del cuerpo biológico, tampoco de las identificaciones. Cabe recordar que ya en 1958, cuando escribió Ideas directivas para un Congreso sobre la sexualidad femenina, se había preguntado si el falo drenaba todo lo que de pulsional se podía hallar en la mujer.

Con sus famosas fórmulas lógicas de la sexuación y sus desarrollos subsiguientes, Lacan nos hace dos legados:

- en tanto hay inexistencia de la representación Universal de la Mujer, de una definición unívoca que pueda totalizarla/reducirla, se requiere abordarlas Una a Una;

- una emergencia se vuelve concebible, un goce Otro, suplementario, específicamente femenino, imposible de decir, asir o abordar con las estructuras del lenguaje.

No hay Universal de la mujer, y hay algo de inasible en su posición sexuada.

¿De qué se trata ese goce femenino? ¿Cuál es su especificidad? ¿Cómo ubicar ese goce que no es fálico ni antifálico, que no se funda en ningún binarismo, oposición o reivindicación, sino que es precisamente Otro?

Debe aclararse que con Otro no refiere a segundo, de segunda mano, ni complementario, sino radicalmente inédito, inexplicable, innombrable, inasible bajo los modos del lenguaje. Con Otro decimos Ex.

"Si lo que propongo es verdadero, a saber, que la mujer no toda es, hay siempre algo en ella que escapa al discurso" (Lacan, 2007 [1973], p. 44). Con Lacan se funda un feminismo, el del Una a Una, el de cada mujer, un feminismo subversivo y no revolucionario. Dejamos, con él, de girar en redondo.

"La subversión, si es que existió en alguna parte y en algún momento, no está en haber cambiado el punto de rotación de lo que gira sino en haber sustituido un gira por un cae" (Lacan, 2007 [1973], p. 56). De manera que el psicoanálisis no niega la opresión de las mujeres; pero se orienta por un más allá, por lo real, tratando de dar cuenta del goce de cada mujer y de ese goce Otro, que articula lo específicamente femenino no como esencia natural sino como Otredad lógica que exige una escritura singular. ¿Letra? ¿Trazo? Toda una vía de investigación.

\section{Candelaria: el ojo, la mirada y dos escenas fundamentales sobre el deseo:}

Candelaria (Hinestroza, 2018) es una película coproducida por varios países latinoamericanos, ambientada en la Cuba del año 1994, momento histórico conocido como
Período Especial y que alude a la crisis económica derivada de la caída del campo socialista. La trama se teje en torno a una pareja de adultos mayores que, al encontrarse con una videocámara, reanudan las relaciones sexuales entre ellos, participan -tímidamente- de un negocio clandestino de pornografía y... ¿ ¿refundan algo de su amor?

¿Qué mira el ojo que mira? ¿Cuál es el lugar de la cámara allí y en la época contemporánea? ¿Cuál es la relación entre lo viral, lo que se vende, lo que se muestra y el goce? ¿Qué goce llega a capturar la cámara y qué goce se le escurre? ¿Cuántas mujeres hay en Candelaria? Volvamos a una advertencia de Lacan en su escrito Televisión: "que no exista no excluye que uno haga de ella el objeto de su deseo. Muy por el contrario, de ahí el resultado" (Lacan, 2012 [1974], p. 563).

En la película dos momentos resultan paradigmáticos en relación al deseo:

En el minuto 30, sentados en un banco de parque, acontecen dos secuencias en la misma escena: Víctor Hugo mira a Candelaria como hace tiempo no lo hace y esto le mueve a besarla, ella se asusta y para explicarse le dice: "Es que, ¿desde hace cuándo que no me das un beso?”. No pasan ni 30 segundos y Candelaria finge que ha caído en su propio ojo una basurita, le pide a Víctor Hugo que se fije...le roba un beso. Ambos ríen.

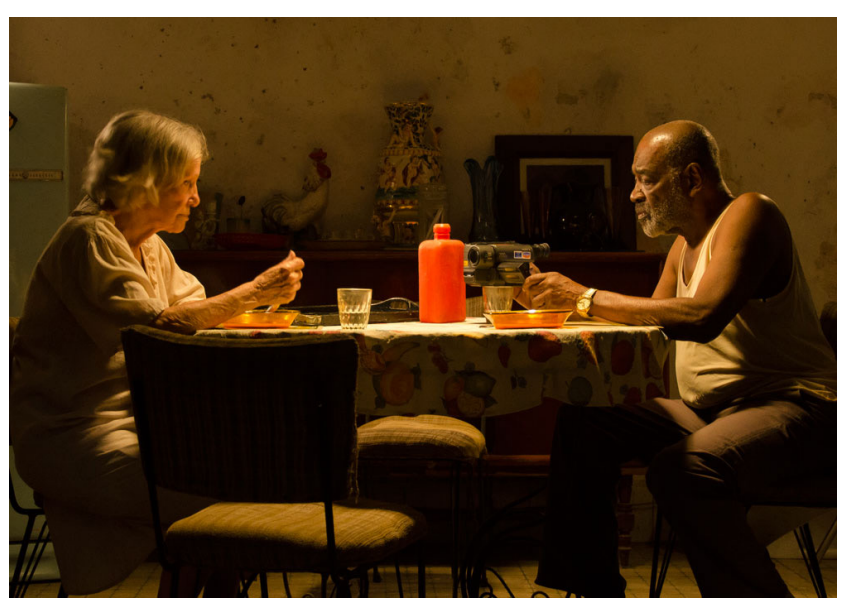

¿De qué ríen sino de sí mismos y de la puesta en acto de los más clásicos semblantes? El deseo implica rodeo, baile, derivación. El agarre es del orden de la satisfacción, el deseo no requiere su concreción. La escena registra -y muestra- ese instante de lucidez donde sus protagonistas perciben que el deseo solo se encarna en la sorpresa, no es del orden de la voluntad.

Eso sí, ambos juegan un juego que se ordena por la mirada, para ellos. Esto incluso antes de que la videocámara sea la que tome el protagonismo del film. En la es- 
cena descrita él la ve atractiva y avanza, ella usa el ojo para el robo. Dos posiciones sutilmente distintas en relación al mismo objeto: en él comanda, en ella es instrumento.

Más adelante Víctor Hugo va a confirmar esas dos posiciones en el juego con una frase: "Eres muy buena actriz, pero necesitas un director que te dirija".

La segunda escena es una de las tres conversaciones entre Víctor Hugo y el negociante que quiere vender las películas íntimas de la pareja en el mercado negro de aquella época cubana. Víctor Hugo está tentado y resistido, se mueve entre la intimidad, el hambre y la moral; pero negocia un precio. Intentando bajar el valor el negociante le dirige una pregunta: "¿Antes de la cámara, tenías sexo con Candelaria?"

El momento marca la instancia de antes y después producida por la aparición de la videocámara. Pero... ¿es el sexo lo que les devuelve ese gadget? ¿O es, más precisamente, un nuevo estatuto para la mirada en los embrollos del deseo?

Nótese los inicios: filmaciones cotidianas como los pollos o las cenas, de ahí a las filmaciones explícitas por las que obtendrán algún dinero. En el medio hubo un pasaje por el erotismo: Víctor Hugo filma a Candelaria contingentemente a la salida del baño, ella se descubre al día siguiente en la cámara y se filma a sí misma para sorprenderle. El juego comanda otra vez, las mismas posiciones para él y ella: él mira, ella se hace mirar, mira como él la ve. ¿De quién es el ojo entonces? Inubicable.

Retomemos la pregunta de líneas arriba: ¿qué mira el ojo que mira? y ¿quién mira? Es una obviedad que miramos todos, quienes espectan el film también. La pulsión insiste tanto como comanda. Recuérdese la indicación lacaniana en Televisión (2012): el sujeto es siempre feliz a nivel de la pulsión, nunca está en menos allí.

Se hace pertinente ubicar en este punto una diversidad peculiar: ¿cuántas mujeres hay en Candelaria? La que canta en el vestido rojo, la del uniforme de trabajo que no milita la huelga, la desnuda, la que se descubre a sí misma en la cámara bajo el ojo espía del marido, la que se decide a jugar con él, la que cuida y llora a los pollitos, la que enfrenta al negociante, la que está dispuesta a morir. ¿Y cuál de todas ellas está en relación al ojo y la cámara?

\section{El deseo no es el goce...}

“Candelaria: 'Cuba está amenazada de muerte todos los días y yo, yo quiero mirar la mía de frente’. Víctor Hugo: 'Candelita, no te me apagues...”'
Lo inesperado ingresa al film cerca del final, justamente en el más allá de la trama: Candelaria está enferma y decide no hacer tratamiento curativo. Una voz en off dice: "El alma también puede reír cuando se acepta la muerte".

La risa ha sido una constante a lo largo del film. En él, en ella. La risa y el canto como salvación frente a la crudeza de esa realidad en crisis económica.

El exergo de este acápite es el diálogo entre Candelaria y Víctor Hugo, cuando ella le da sus razones para no someterse al tratamiento. No hay el deseo de morir, hay el goce de la vida.

Es necesario volver a recurrir a Lacan y su definición de goce en la primera clase del Seminario 20: “¿Qué es el goce? Se reduce aquí a no ser más que una instancia negativa. El goce es lo que no sirve para nada" (Lacan, 2007 [1973], p. 11). Así, queda fuera de toda utilidad, y se opone por tanto a las nociones de progreso, desarrollo, bienestar. Es más bien lo que va en oposición a ello. $\mathrm{Y}$, aún, indica la vida.

Candelaria no está hecha de beligerancia. No asiste a la huelga del inicio del film, así como no elige la lucha médica. Arde en ella la vida, hasta el final. ¿Qué efecto en la pareja de ello? Las últimas tomas de la cámara: tan íntimas como amorosas. Candelaria y el mar.

\section{IV. ¿Qué lugar para el amor, entonces?}

También en el Seminario 18 (Lacan, 2009 [19701971]) Lacan afirma que el amor es un arreglo que suple la ausencia de relación sexual. En el 19 ( Lacan, 2012 [1971-1972]) invierte la cuestión: es la ausencia de relación la condición de posibilidad para el establecimiento de los lazos y, por tanto, del amor. Eso sí, algo insiste y hace de obstáculo siempre: el goce. Amor y goce se oponen, el segundo interrumpe al primero, lo sintomatiza.

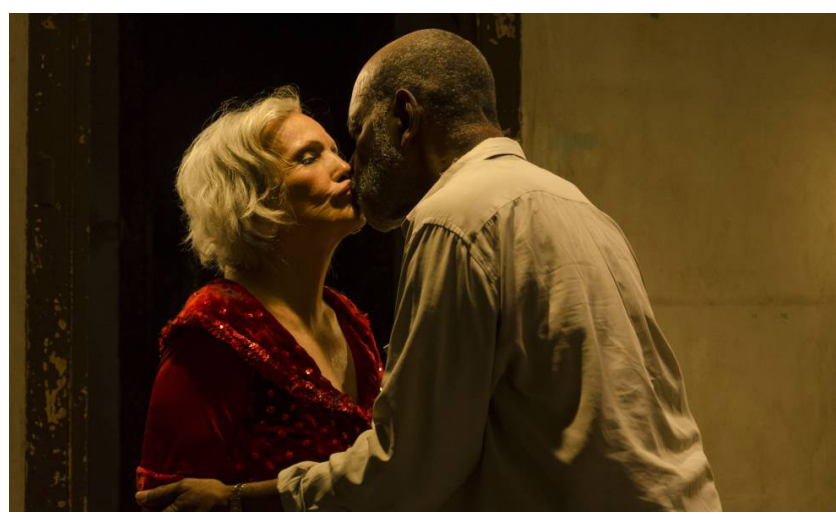


"Goza de la vida, dice el autor, enigmático como saben, en este texto sorprendente, Goza de la vida con la mujer que amas. Se trata del colmo de la paradoja, ya que justamente por amarla surge el obstáculo" (Lacan, 2009 [1971], p. 164).

En el minuto 36 del filme Víctor Hugo le pregunta a Candelaria "¿ Cuándo dejé de verte?"

El hombre cree abordar a una mujer, pero lo que aborda es la causa de su deseo. El amor para una mujer, en cambio, tiene entre las funciones más excelsas la de fijar su propia deriva pulsional, asirle a la ley, darle una pata sólida. De lo que se trata en estas relaciones paradigmáticas es que cada encuentro -contingente por de- finición- y la necesariedad del mismo, implicarán también arreglos singulares. En Víctor Hugo y Candelaria el mar hace signo del amor. La entrada en el film de ese signo vasto es posible solo de la mano de ella, tal como lo muestra uno de los últimos encuadres fotográficos.

Así, mirada y videocámara fundan un lazo erótico durante un tiempo del film. Pero, hacia el final, mirada, video cámara y mar refundan otro lazo, confirmando esa extraña indicación: solo el amor hace al goce condescender al deseo, y aun así algo desborda. Dos preguntas son inevitables para el cierre: ¿dónde están los límites del mar? ¿dónde está Candelaria al final de la película?

\section{Referencias}

Hinestroza, J. H. (Director) (2018). Candelaria. [Película]. Antorcha. Films, Razor Film, DHF, Pucará Cine, Fidelio Films, Producciones de la 5ta Avenida.

Lacan, J. (2012). Ideas directivas para un congreso sobre la sexualidad femenina. En Lacan, J., Otros Escritos (pp. 689-702). Paidós.

Lacan, J. (2012). El Seminario de Jacques Lacan. Libro 19... O peor. Paidós. (Seminario dictado en 1971-1972).

Lacan, J. (2012). Televisión. En Lacan, J., Otros Escritos (pp. 535-573). Paidós.

Lacan, J. (2009). El Seminario de Jacques Lacan. Libro 18. De un discurso que no fuera del semblante. Paidós. (Seminario dictado en 1970-1971).

Lacan, J. (2007). El Seminario de Jacques Lacan. Libro 20. Aun. Paidós. (Seminario dictado en 1972-1973).

Lauretis, T. (2010). Diferencias. Etapas de un camino a través del feminismo. Horas y HORAS.

Millot, K. (2016). La vida con Lacan. Ned.

Sendón de León, V. (2012). ¿Qué es el feminismo de la diferencia? La Mariposa y La Iguana. 